\title{
A hierarchical structure of service-oriented manufacturing mode
}

\author{
Yang Mingshun ${ }^{\mathrm{a}}$, Gao Xinqin ${ }^{\mathrm{b}}$, Liu Yong ${ }^{\mathrm{c}}$, Li Yan ${ }^{\mathrm{d}}$ \\ Xi'an University of Technology, Xi'an, China \\ ayangmingshun@xaut.edu.cn, bccyxz@xaut.edu.cn, liuyong@xaut.edu.cn, dnocc@163.com
}

Keywords: service-oriented manufacturing, conceptual model, hierarchical structure

\begin{abstract}
With fiercer competition and more complex manufacturing environment, as a new manufacturing mode, service-oriented manufacture integrating manufacturing and service is used to mine new value source for manufacturing enterprises. The characteristics of the new manufacturing mode are analyzed, then a conceptual mode of the service-oriented manufacturing is concluded, and the features of the conceptual model are summarized from three different stages of the upstream, midstream and downstream. Based on these, a hierarchical architecture of service-oriented manufacturing mode is presented, and the different layers are described, which will provide good guideline to study the key technologies of service-oriented manufacturing.
\end{abstract}

\section{Introduction}

With fiercer competition, more complex and customized equipments, to obtain bigger value space, instead of the traditional competition with a core of physical product manufacturing, more and more enterprises are converting to service competition with a core of providing convenient service to the customer $[1,2]$.

While adapting to the environmental changes, the value chain of manufacturing industry is changing. On one hand, the traditional manufacturing value obtaining is not limited to its own manufacturing domain again; it extends to the service domain. On the other hand, the single enterprise outsources businesses without core competitiveness and concentrates on enhancing its core competitiveness through extraordinary fragmentation of production. Based on the changing of the value-obtaining mode, the manufacturing enterprises begin to take part in servicing business, which makes the manufacturing activities extend to service domain. At the same time, with professional details of the manufacturing industry, service industry begins to infiltrate into manufacturing industry. The new trend of integrating of manufacturing and service is more and more obvious, and a new manufacturing paradigm called service-oriented manufacturing comes into being to adapt to modern production background $[3,4]$. The new manufacturing paradigm aims at realizing value enhancement of relative interested among a manufacturing value chain. Through merging manufacturing and service, customers participating in the product life cycle, enterprises providing producer services and non-production services to each other, integrating the distributed manufacturing resources, cooperating with the core competitive nesses of different enterprises are realized to reach high effectiveness creative.

\section{Characteristics of service-oriented manufacturing}

As a new type manufacturing mode, service-oriented manufacturing aims to get rid of drawbacks such as low technology and low value-added, which is different form the traditional manufacturing mode in some important aspects of value enhancement, operational method, organization model and operational mode $[4,5]$. 
(1) Value enhancement mode. Service-oriented manufacturing mode converts from traditional product manufacturing to providing producer service to get value-added. The enterprises will provide whole solution of "product and service" to customers to obtain more profits.

(2) Organizational mode. The traditional organizational model which takes departments as its basic unit has been changed. The new manufacturing mode emphasizes that the organizational basis is business process. The customers, service enterprises, manufacturing businesses will participate actively in the cooperation activities network to complete optimizing allocation of resources.

(3) Operational mode. Service-oriented manufacturing takes people as the centre and focuses on active service and personalized services. Though customers participating to the process of manufacturing, different customer needs and the services beside entity product would be perceived, found and mined to satisfy individual requirements of customers. It would be fulfilled the information feedback from customers. Through carrying out collaborative manufacture actively with producer service enterprises, the value will be enhanced greatly.

\section{A conceptual model of service-oriented manufacturing}

From three stages of product design in the upstream, product manufacturing in the middle stream and product selling in the downstream, integrating producer service and manufacturing of every stage, a simple and intelligible conceptual model of serve-oriented manufacturing mode is proposed, as is shown in the Fig.1.

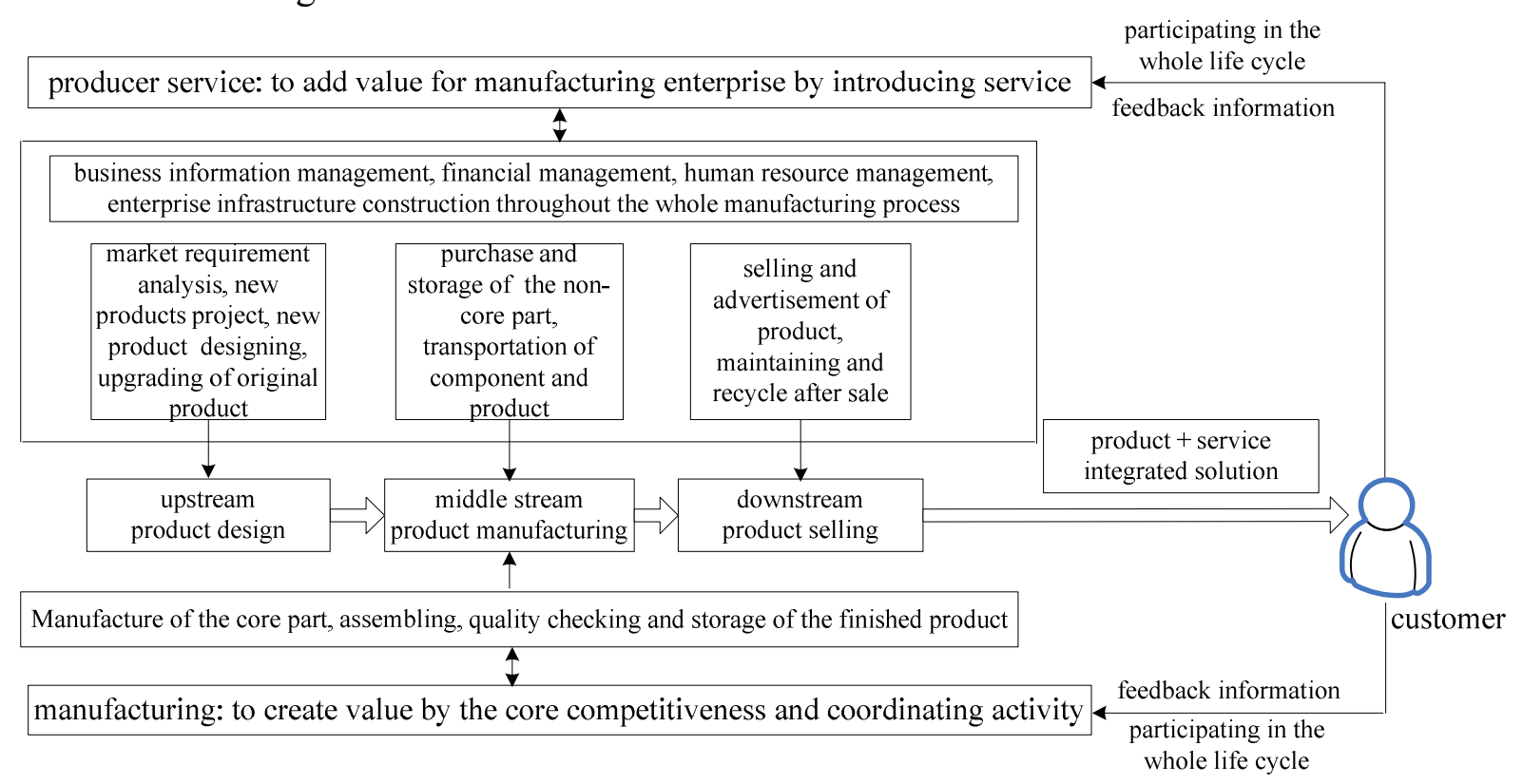

Fig.1 Conceptual model of service-oriented manufacturing mode

(1) Producer service throughout the whole life cycle of manufacturing process

In the stage of product design, the producer services involving market requirement analysis, new products project, etc. In the stage of the product manufacture, the producer services including purchase and storage of the non-core part, transportation of component and product, etc. After selling products, the main producer services are selling and advertisement of product, maintaining etc. In this process, enterprise information management, financial management, human resources management and so on are all as producer service activities to create value for enterprises.

(2) Manufacturing creates the core competitiveness

In this paper, manufacturing refers to manufacturing enterprises outsourcing the non-core producing, integrating their own core manufacturing capability and other enterprises to complete production. Service-oriented manufacturing mode strengthens the collaboration of professional division enterprises to meet the market demand quickly. 
(3) Providing customers the integrated solutions

Enterprises of service-oriented manufacturing mode provide customers with not only the entity, but also the PSS. By doing this, the transportation and selling of product can be reduced to save resources. Also, the independent maintenance consciousness will be improved during the product belongs to enterprises. It can strengthen product recycling and upgrading and be convenient for resources recycle. At the same time, the enterprises that provide services can use the product intensively to reduce the harm to environment, etc.

(4) Customers participate to the whole production activities by feeding back information

The customers create market by feeding back their personalized requirements. Enterprises take customer demands as a guide to dominate the market.

\section{Hierarchical architecture of service-oriented manufacturing}

Based on the above analysis, a hierarchal architecture is presented, as shown in the Fig.2. In the product lifecycle, the service providers design, describe, encapsulate, release and maintain their services according to their core competitiveness and service demands, the services are released in a unified platform via Intranet/Extranet/Internet. The service-oriented manufacturing enterprise searches, matches, allocates and optimizes the provided services according to customer requirements to finish the lifecycle business process. The architecture includes five layers, i.e. service providing layer, service layer, execution layer, supporting layer and base layer.

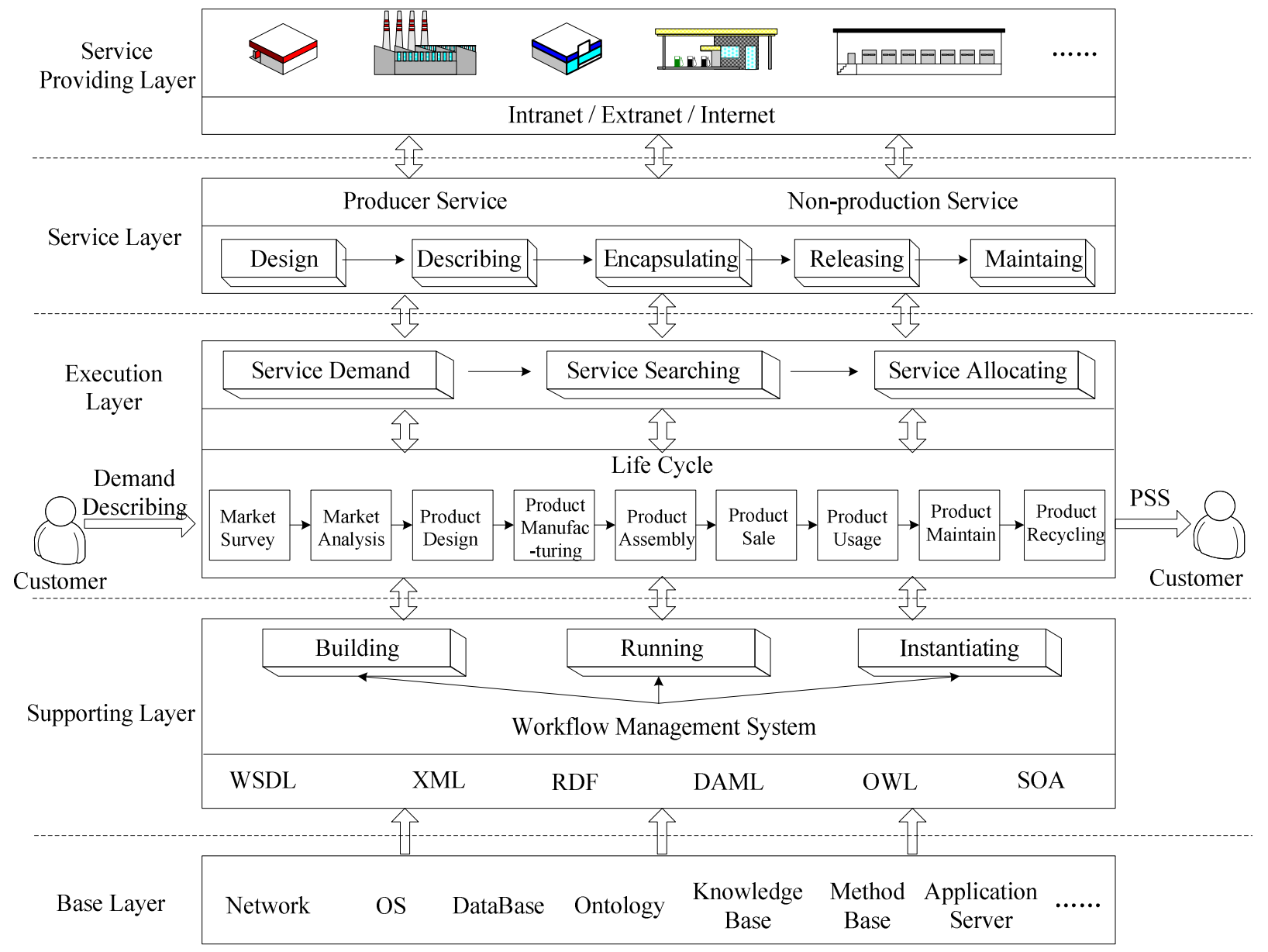

Fig.2 Hierarchal architecture of service-oriented manufacturing mode 
(1) Service providing layer

With the increasing merging of manufacturing and service, producer service enterprises begin to provide various producer services to service-oriented manufacturing enterprises to satisfy their demands. These enterprises act as the main service provider; they release the services via the unified user interface and Intranet/Extranet/Internet.

(2) Service layer

The service layer provides unified service resource management, which can shield geographical distribution of different services and establish the information foundation for collaborative manufacturing among the producer service enterprises. On this layer, the service resources provided are encapsulated into the data information which can be distinguished by the system and users after designing and describing. Theses services can provide supporting platform to enterprises for service searching with the service nodes released via different networks.

(3) Execution layer

On this layer, the service-oriented manufacturing enterprise is guided by the customer demand, goes through the business process of the life cycle and finally provides integrated solutions of PSS to the customers. This layer provides a platform for searching service resources, which can enhance the flexibility, dynamic responding ability to the market and competitive power of an enterprise.

In a life cycle, service searching \& matching and service allocation optimizing exist in the every stage of market surveying, product design, product manufacturing, product selling, product usage, product maintaining and recycling. During the whole process, the service-oriented manufacturing enterprise analyzes the service requirements of the different stages, matches the corresponding services through Intranet/Extranet/Internet and finds the service set satisfying the requirements, then allocates the resources optimally, finally the manufacturing business process is finished with supporting of the optimal service scheme.

(4) Supporting layer

On the supporting layer, with some specific techniques such as WSDL, XML, RDF and SOA, through three stages of business process modeling, running and instantiating, workflow management system supports the whole architecture of service-oriented manufacturing paradigm, which can provide technical supports for automatic execution of service-oriented manufacturing business process.

(5) Base layer

As the lowest layer of the architecture, the base layer including basic database, domain ontology base, knowledge base and method base is used to provide basic data information supporting. Taking the enterprise operation system and application server as the base linking the service data, service discovery, integration and usage are realized to support the automation of service-oriented manufacturing business process. 


\section{Summary}

As a new manufacturing paradigm, service-oriented manufacturing realizes the convergence of service and manufacturing industry and is showing the advantages over the traditional manufacturing paradigm. The differences of value enhancement, business operational model and Organizational model between service-oriented manufacturing paradigm and the traditional manufacturing are compared, from three stages of product design, product manufacturing and product selling, with producer services and non-production services integrated, a conceptual model for service-oriented manufacturing is given. Based on the model, a hierarchical architecture including service providing layer, service layer, execution layer, supporting layer and base layer is presented, which can provide guideline for studying the new manufacturing paradigm. Further research will concentrate on the key technologies of building and implementing service-oriented manufacturing paradigm.

\section{Acknowledgments}

We acknowledge financial support from the National Natural Science Foundation, China project [60903124], the Doctorial Program Foundation of Higher Education of China project [20096118120003], the Science and Technology Research Plan of Shannxi Provincial Education Department, China project [09JK614] and the Doctorial Foundation of Xi'an University of Technology project [102-210903] provided for this work.

\section{Reference}

[1] L. Y. Sun, G. Li Gang, Z. B. Jiang, L. Zheng and Z, He, Service-embedded manufacturing: advanced manufacturing paradigm in 21st century, China Mechanical Engineering. 18(2007) 2307-2312. (In Chinese)

[2] M. Hobo, C. Watanabe, C. J. Chen, Double spiral trajectory between retail, manufacturing and customers leads a way to service oriented manufacturing, Technovation. 26(2006) 873-890.

[3] T.S. Baines, H. W. Lightfoot, State-of-the-art in product-service systems, Engineering Manufacture, 18 (2007) 1543-1552.

[4] Y. L. Wang, Boosting Service-type manufacturing - a strategic consideration on optimizing the adjustment of China's industrial structure, Journal of Xi'an Jiaotong University (Social Sciences). 30(2010) 26-40.(In Chinese)

[5] A. Williams, Product service systems in the automobile industry: contribution to system innovation, Cleaner Production, 15 (2007) 1093-1103. 